\title{
Decrease in Incidence of Bronchopulmonary Dysplasia with Erythropoietin Administration in Preterm Infants: A Retrospective Study
}

\author{
Niti Rayjada ${ }^{a}$ Lorayne Barton ${ }^{a}$ Linda S. Chan ${ }^{b}$ Salvador Plasencia ${ }^{a}$ \\ Manoj Biniwale ${ }^{a} \quad$ Kim Chi Bui ${ }^{a}$ \\ ${ }^{a}$ Center for Fetal and Neonatal Medicine and USC Division of Neonatal Medicine, LAC+USC Medical Center, and \\ ${ }^{b}$ Department of Pediatrics, Children's Hospital Los Angeles, Keck School of Medicine, University of Southern \\ California, Los Angeles, Calif., USA
}

\section{Key Words}

Erythropoietin - Bronchopulmonary dysplasia $\cdot$ Ventilator days $\cdot$ Oxygen days $\cdot$ Prematurity $\cdot$ Neonates $\cdot$ Anemia of prematurity

\section{Abstract \\ Background: Despite advances in clinical care, the incidence of bronchopulmonary dysplasia (BPD) remains high in pre- mature infants. Erythropoietin (EPO) is used for the treat- ment of anemia of prematurity (AOP) to decrease blood transfusion needs. EPO has been shown to mobilize circulat- ing endothelial progenitor cells and to enhance lung repair in animal models. Objective: To determine whether EPO treatment for AOP was associated with a reduced incidence of BPD in premature infants. Methods: This retrospective study was performed on all live-born neonates with birth weights from 500 to $1,500 \mathrm{~g}$ and gestational age (GA) from 22 to 32 weeks admitted from 1994 to 2002. Infants who re- ceived EPO and those who did not receive EPO were com- pared for incidence of BPD and other morbidities. Results: Of 478 patients, 297 received EPO before 36 weeks' post- menstrual age (group 1) and 181 did not receive EPO (group 2). Group 1 was of similar birth weight but lower GA than}

\section{KARGER}

Fax +4161306 1234

E-Mail karger@karger.ch

www.karger.com
(C) 2012 S. Karger AG, Basel

$1661-7800 / 12 / 1024-0287 \$ 38.00 / 0$

Accessible online at:

www.karger.com/neo group 2. The incidence of BPD was lower in group 1 than group 2 ( 26 vs. $36 \%, p=0.03$ ); after adjusting for significant risk factors, the adjusted odds ratio for BPD was $0.50(95 \% \mathrm{Cl}$ $0.32,0.79), p=0.0028$. The BPD rate was much lower when EPO was initiated before 4 weeks of age (16\%) as compared to later initiation (44\%). Conclusions: This study shows an association between EPO treatment and reduced incidence of BPD in preterm infants, particularly when EPO treatment was initiated within the first 4 weeks of life.

Copyright $\odot 2012$ S. Karger AG, Basel

\section{Introduction}

Advances in perinatal management have improved the survival of preterm infants, however bronchopulmonary dysplasia (BPD) remains a major morbidity in very low birth weight (VLBW) infants [1-4].

Prematurity, lung injury, inflammation, and yet unknown factors contribute to processes that hinder lung development causing BPD $[4,5]$. These processes are recognized as abnormal alveolar and vascular changes during a critical stage of postnatal lung development. Steroid therapy used for prevention or treatment of BPD matures 
the epithelial compartment of the lung, but may impair microvascular development [4]. Long-term follow-up has recognized a rise in cerebral palsy and a decline in neurodevelopmental outcome in infants treated with dexamethasone (DEX) [6-8]. Therefore, finding alternative treatments that improve both the vascular and epithelial growth in postnatal premature lungs could potentially reduce the incidence of BPD.

Preterm infants have low endogenous erythropoietin (EPO) levels. As a result, to decrease blood transfusions, EPO was administered for treatment of anemia of prematurity (AOP) [9-11]. Treatment with EPO, which has the potential to mobilize endothelial progenitor cells (EPC) in animal models $[12,13]$, has been shown to partially reverse the histological features of BPD in rodents [14]. Additionally, decreased levels of circulating EPC were demonstrated in neonatal rodent models of BPD [15]. In adults with acute lung injury, increased EPC are associated with improved survival [16] likely due to enhanced repair of the pulmonary endothelium. High levels of EPC in cord blood have been associated with a reduced incidence of BPD in preterm infants [17].

We hypothesized that VLBW preterm infants who had received EPO for AOP would have had a lower incidence of BPD determined as oxygen need at 36 weeks' postmenstrual age (PMA). Secondarily, we assessed whether there was any association between EPO administration and other neonatal morbidities such as ventilator days, oxygen days, intraventricular hemorrhage (IVH) and retinopathy of prematurity (ROP). Lastly, we assessed whether the age at initiation of EPO treatment influenced the BPD outcome.

\section{Patients and Methods}

\section{Study Setting}

The study population was comprised of all live-born neonates with a birth weight (BW) from 500 to $1,500 \mathrm{~g}$ and 22-32 weeks' gestational age (GA) admitted to our neonatal intensive care unit from 1994 to 2002 . The local institutional review board approved the study.

The indications for EPO treatment were: to decrease early blood transfusions in infants $<1,000 \mathrm{~g}$ during the first days of life or to decrease late transfusions at 4-8 weeks of life in infants $<1,500$ g. EPO was given by subcutaneous injections $250-300$ IU/ $\mathrm{kg} /$ dose 3 times a week for 2 weeks and reticulocytes were checked weekly during the treatment. Additional courses of 2 weeks' treatment were considered if hematocrit was low or reticulocytes count was below $5 \%$.

Transfusion triggers levels were: (1) hematocrit $<35 \%$ or hemoglobin $<12 \mathrm{~g} / \mathrm{dl}$ for patients on mechanical ventilation requiring $\mathrm{FiO}_{2}>40 \%$ or with hypotension; (2) hematocrit $<30 \%$ or he- moglobin $<10 \mathrm{~g} / \mathrm{dl}$ for patients on mechanical ventilation and requiring $\mathrm{FiO}_{2}<40 \%$, patients requiring $\mathrm{FiO}_{2}>40 \%$, unexplained apnea, 10 or 2 spells per day requiring bag-mask resuscitation, unexplained heart rate $>165 / \mathrm{min}$ for 2 days, poor weight gain $(<10$ $\mathrm{g} / \mathrm{kg} /$ day over 1 week), unexplained lethargy, and (3) hematocrit $<25 \%$ in asymptomatic patients.

We excluded infants with major congenital anomalies, infants born $<22$ weeks' gestation, those who died before 36 weeks' PMA and cases in which EPO was initiated at 36 weeks' PMA or beyond, or when pulmonary outcomes data were missing.

\section{Study Design}

This study was a retrospective observational cohort study to assess the impact of EPO administration on BPD as well as other neonatal morbidities in VLBW premature infants. The patients were placed in group 1 (received EPO before 36 weeks' PMA) and in group 2 (did not receive EPO). The infants were selected from 1994 until 2002 as the use of EPO was discontinued at the end of 2002 secondary to lack of clear benefits [9] and concerns of its possible association with ROP [10].

\section{Data Collection}

Data collected from the neonatal database included BW, GA, gender, type of delivery and Apgar scores at 1,5 and $10 \mathrm{~min}$. Maternal factors such as clinical chorioamnionitis, pregnancy-induced hypertension, diabetes and prenatal steroid administration were collected. Neonatal factors such as sepsis (documented as clinical sepsis or with positive blood culture), pneumonia, pneumothorax, patent ductus arteriosus (PDA), PDA requiring surgical ligation, IVH, ROP highest grade and any surgery performed, days of mechanical ventilation, days of supplemental oxygen, need for supplemental oxygen or mechanical ventilation at 28 days and 36 weeks' PMA, length of hospital stay and administration of pulmonary medications (surfactant, vitamin A and DEX) as well as the final outcome (discharge home or death) were also evaluated. Babies who received 3 or more consecutive days of DEX treatment were counted as DEX-treated. BPD was determined at 36 weeks' PMA as need for oxygen supplementation to maintain pulse oximeter saturation above $94 \%$. Lastly, we recorded the age at initiation of EPO and the number of doses administered. Patients' medical records were reviewed when data elements were missing from the database.

\section{Statistical Analyses}

Our primary objective was to compare the incidence of BPD in groups 1 and 2. Univariate analysis was performed to assess the difference in the incidence of BPD with each risk factor between groups 1 and 2 using the $\chi^{2}$ test or the two-sided Fisher's exact test to compare proportions and the two-sample Student t test or the Wilcoxon rank-sum test to compare means wherever appropriate. Risk factors that were significant at $\mathrm{p}<0.05$ from the univariate analysis were entered in the multivariate logistic regression analysis to derive the adjusted odds ratio (OR) and $95 \%$ confidence interval (CI) for BPD rate between groups 1 and 2. For secondary outcomes measured on a continuous scale, we used analysis of covariance. Statistical significance was set at $p<0.05$. All statistical analyses were performed using SAS 9.1 software (SAS Institute, Cary, N.C., USA). 


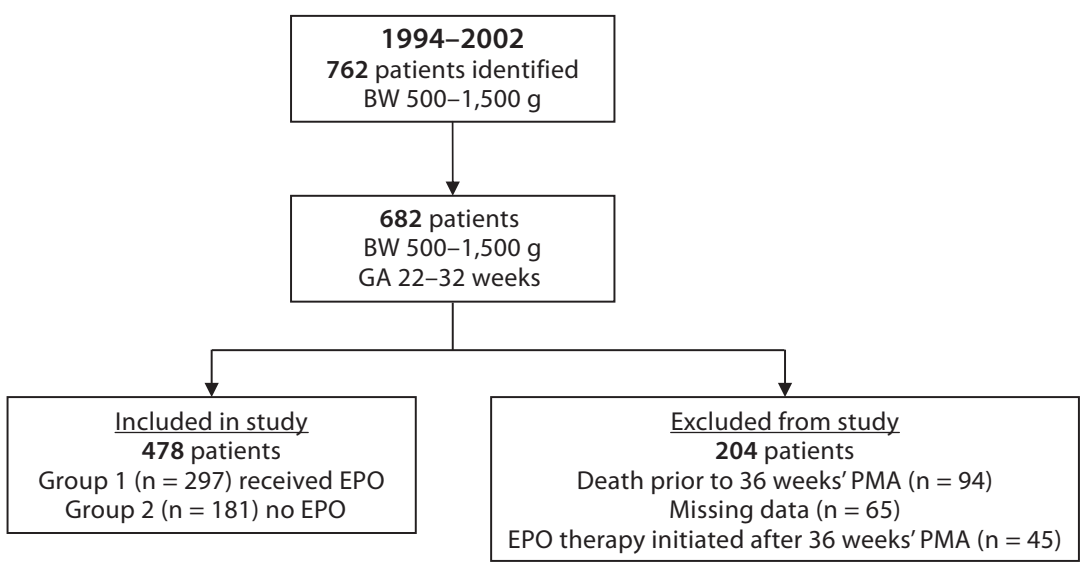

Fig. 1. Inclusion and exclusion of patients.

\section{Results}

During the study period, 762 patients were identified with a BW between 500 and 1,500 g and 682 were $\leq 32$ weeks' GA. We excluded 94 patients who died prior to 36 weeks' PMA, 65 patients for incomplete data due to being transferred from or referred to other facilities, and $45 \mathrm{pa}-$ tients who received EPO at or after 36 weeks' PMA. Of the 478 patients included in this study, 297 received EPO (group 1) and 181 did not (group 2) (fig. 1). The clinical characteristics are presented in table 1. BW and Apgar scores were similar between the two groups. The patients in group 1 had a lower GA $(28 \pm 2$ vs. $29 \pm 3$ weeks, $p=$ $0.006)$ than group 2 and a higher incidence of maternal diabetes ( 8.5 vs. $3.4 \%, p=0.034)$. There was no difference in surfactant, vitamin A or DEX use, no difference in the incidence of pneumothorax, PDA, sepsis, highest grade of ROP or ROP-requiring surgery, rates of IVH grade 2 or higher, number of patients who required a blood transfusion or the number of transfusions between the two groups.

Three patients expired after 36 weeks' PMA, 2 from group 1 and 1 from group 2. Group 1 had 113 infants $(38 \%)$ and group 2 had 60 infants $(33 \%)<28$ weeks' gestation.

\section{Pulmonary Outcomes}

Several factors affected the incidence of BPD in preterm infants in univariate analyses, including GA, BW, sepsis, maternal diabetes, length of hospital stay, ventilator days, prenatal steroids, DEX, and vitamin A administration. After adjustments for significant differences in these risk factors, using multivariate logistic regression,
EPO had a statistically significant association with a decrease in BPD rate.

Table 1 shows that BPD rate was lower in group 1 than in group 2 (26 vs. $36 \%, \mathrm{p}=0.030$; OR 0.64 (95\% CI 0.43 , $0.95), \mathrm{p}=0.03)$. After adjusting for differences in the significant risk factors, maternal diabetes and GA, the adjusted OR for BPD was 0.50 (95\% CI 0.32, 0.79), $\mathrm{p}=0.0028$. Further, the adjusted mean ventilator days was significantly lower in group 1 than group 2 (mean 20 compared to 27 days, $\mathrm{p}=0.0005$ ). The adjusted mean oxygen days was also lower in group 1 (mean of 39 compared to 49 days, $\mathrm{p}=0.0002$ ). There was no difference in requirement for home oxygen between groups.

The incidence of BPD was 78\% (73/94) in group 2 infants who received only DEX, 51\% (63/124) among group 1 infants treated with both DEX and EPO, 11\% (17/153) in infants who received neither EPO nor DEX, and 9\% $(15 / 173)$ in infants who only received EPO.

\section{Age of Initiation of EPO and BPD Outcome}

We observed that earlier initiation of EPO was associated with a lower incidence of BPD. We chose 4 weeks as a cut-off where the incidence of BPD seemed to change substantially. Infants in group 1 were divided into subgroups $1 \mathrm{~A}$ and $1 \mathrm{~B}$ with start of EPO treatment at $<4$ weeks or $>4$ weeks of age. The age at start of EPO was 36 \pm 18 days for patients who developed BPD and $23 \pm 14$ days for patients who did not develop BPD ( $p<0.0001)$. The BPD rate was $16 \%(29 / 186)$ in group $1 \mathrm{~A}$ as compared to $44 \%(49 / 111)$ in group $1 \mathrm{~B}(\mathrm{p}<0.0001)$. The median number of doses of EPO was 12 in patients who developed BPD and 9 in those who did not. 
Table 1. Comparison of demographic and clinical characteristics between patients with and without EPO

\begin{tabular}{lccl}
\hline & EPO & No EPO & p \\
& group 1 & group 2 & value \\
\hline Number of patients & 297 & 181 & \\
Birth weight, g & $1,038 \pm 256$ & $1,063 \pm 281$ & 0.29 \\
Gestational age, weeks & $28 \pm 2$ & $29 \pm 3$ & $0.0065^{*}$ \\
Male & $158(53 \%)$ & $107(59 \%)$ & 0.22 \\
Apgar score at 1 min & & & \\
$\quad$ median (range) & $6(0,9)$ & $6(1,9)$ & 0.43 \\
Apgar score at 5 min & & & \\
$\quad$ median (range) & $8(2,10)$ & $8(1,10)$ & 0.40 \\
Apgar score at 10 min & & & \\
$\quad$ median (range) & $7(1,9)$ & $7(2,9)$ & 0.80 \\
Vaginal delivery & $92(32 \%)$ & $62(35 \%)$ & 0.42 \\
Prenatal steroids & $84(38 \%)$ & $47(35 \%)$ & 0.65 \\
Maternal PIH & $67(23 \%)$ & $42(24 \%)$ & 0.91 \\
Maternal diabetes & $25(9 \%)$ & $6(3 \%)$ & $0.0341^{*}$ \\
Maternal infection & $55(19 \%)$ & $29(16 \%)$ & 0.54 \\
Surfactant & $179(60 \%)$ & $96(53 \%)$ & 0.13 \\
Pneumothorax & $22(7 \%)$ & $13(7 \%)$ & 1.00 \\
Pneumonia & $41(14 \%)$ & $36(20 \%)$ & 0.10 \\
Sepsis & $177(60 \%)$ & $108(60 \%)$ & 1.00 \\
PDA & $186(63 \%)$ & $105(58 \%)$ & 0.33 \\
PDA ligation & $36(12 \%)$ & $25(14 \%)$ & 0.67 \\
Vitamin A & $29(10 \%)$ & $23(13 \%)$ & 0.36 \\
Dexamethasone & $124(42 \%)$ & $65(36 \%)$ & 0.21 \\
IVH grade $>2$ & $33(29 \%)$ & $21(30 \%)$ & 1.00 \\
Patients with blood & & & \\
$\quad$ transfusion & $258(87 \%)$ & $155(86 \%)$ & 0.89 \\
Number of PRBC & & & \\
$\quad$ transfusions & $4 \pm 3$ & $4 \pm 3$ & 0.45 \\
Eye surgery for ROP & $45(15 \%)$ & $24(13 \%)$ & 0.59 \\
BPD & $78(26 \%)$ & $65(36 \%)$ & $0.0305^{*}$ \\
Length of hospital stay & $66 \pm 27$ days & $68 \pm 40 \mathrm{days}$ & 0.62 \\
Patients discharged alive & 295 & 180 & \\
Home oxygen & $54(18 \%)$ & $36(20 \%)$ & 0.79 \\
\hline$\quad$ & & & \\
\hline
\end{tabular}

Mean $\pm \mathrm{SD}$ for continuous parameters; number of cases (\%) for dichotomous parameters. ${ }^{*} \mathrm{p}<0.05$.

\section{Discussion}

Our study is the first study to show a decrease in the incidence of BPD in preterm infants who received EPO for AOP. In previous reports, EPO was shown to decrease the number of RBC transfusions in preterm infants [11, 18-21]. Tempera et al. [20] reported an association between EPO treatment and a decrease in ventilator days and speculated on the potential to reduce BPD rates [20].

Previous randomized controlled trials of EPO for AOP have failed to demonstrate any significant difference in rates of BPD [9-11]. These studies have reported BPD as a secondary outcome while primarily focusing on transfusion needs. They were not designed to detect a difference in BPD outcome. The study by Haiden et al. [21], in 40 infants with a BW $450-800 \mathrm{~g}$ and GA $\leq 32$ weeks, reported a decrease in transfusions in the EPO group which also had a higher proportion of infants requiring mechanical ventilation. There was no significant difference in incidence of BPD overall (6/21 or $29 \%$ vs. $8 / 19$ or $42 \%)$. Yet, the EPO group had a lower percentage of BPD among ventilated infants (6/17) compared to the control group (8/9). Further, a meta-analysis of these trials did not show any significant difference in BPD rates [19]. Our study included 478 patients, which is larger than published randomized studies that had $<300$ patients [11], and showed a significant difference after adjusting for risk factors for BPD.

The significant association of EPO and reduction of BPD could possibly be explained by several mechanisms. Non-hematopoietic properties of EPO [22] include mobilization of EPC from the bone marrow into the circulation, enhanced migration and proliferation of endothelial cells [12]. Animal studies have shown upregulation of EPO receptors in immature lungs [23]. It can be speculated from our results that the effect of EPO on reduction of BPD may be related to mobilization of EPC in preterm infants and enhanced repair of already damaged alveolar surfaces and pulmonary vascular endothelium.

Patients receiving both DEX and EPO had lower BPD rates than patients on DEX alone, but DEX was administered to preterm infants at highest risk for BPD needing mechanical ventilation after a week of life or to patients with established BPD. A possible mechanism may be related to maturation of the epithelial compartment by DEX while impairing microvascular development. Indeed, DEX treatment of neonatal rats was shown to inhibit alveolar development $[24,25]$ and reduce lung midkine expression, a proangiogenic growth factor present on alveolar type II cells [25]. EPO conversely favors vascular growth. We speculate that EPO usage may counteract the impairment in vascular development produced by DEX and protects against BPD.

The lowest incidence of BPD was observed in infants who received EPO within the first 4 weeks of life. Patients who were treated with EPO later did not benefit from this reduction. The total number of doses did not appear as important.

We found no significant difference in ROP requiring eye surgery between the two groups. Other studies also reported no increase in ROP with EPO treatment in preterm infants $[18,26]$. However, Suk et al. [27] reported 
increased ROP rates in preterm infants $<1,000 \mathrm{~g} B W$ when EPO was administered after 20 days of age with more than 20 cumulative doses.

Our retrospective study has certain limitations. Although we adjusted for known confounding factors affecting the incidence of BPD, we cannot rule out other factors that may have an impact on the incidence of BPD. Our patients were not randomized for treatment with EPO, and the use of EPO was not uniform. The postnatal age at the start of EPO treatment or number of doses received was not standardized.

\section{Conclusions}

Our study findings suggest a possible association of EPO treatment within the first 4 weeks of life with a decrease in incidence of BPD in preterm infants. EPO treatment was associated with a decrease in oxygen days and ventilator days. There was no difference in blood transfusions or ROP in preterm infants treated with EPO or not. These findings would need to be validated in future prospective clinical trials in patients at high risk for BPD.

\section{Acknowledgements}

The authors are grateful to Dr. Manuel Durand for review and criticism of the manuscript, Emily Ramicone for statistical analysis, and Dr. Rangasamy Ramanathan for providing the clinical guidelines and allowing the use of the neonatal database.

\section{Disclosure Statement}

The authors of have no conflicts of interest to disclose.

\section{References}

1 Claas MJ, Bruinse HW, van der Heide-Jalving M, Termote JUM, de Vries LS: Changes in survival and neonatal morbidities in infants with a birth weight of $750 \mathrm{~g}$ or less. Neonatology 2010;98:278-288.

-2 Mulder EEM, Lopriore E, Rijken M, Walther $\mathrm{FJ}$, te Pas AB: Changes in respiratory support of preterm infants in the last decade: are we improving? Neonatology 2012;101:247-253.

-3 Philip AGS: Bronchopulmonary dysplasia: then and now. Neonatology 2012;102:1-8

4 Jobe A, Bancalari E: Bronchopulmonary dysplasia. Am J Respir Crit Care Med 2001; 173:1723-1729.

5 Reyburn B, Martin RJ, Prakash YS, MacFarlane PM: Mechanisms of injury to the preterm lung and airway: Implications for longterm pulmonary outcome. Neonatology 2012;101:345-352.

6 Wilson-Costello D, Walsh M, Langer J, Guillet R, Laptook A, Stoll B, Shankaran S, Finer N, Van Meurs K, Engle W, Das A: Impact of postnatal corticosteroid use on neurodevelopment at 18 to 22 months' adjusted age: effects of dose, timing, and risk of bronchopulmonary dysplasia in extremely low birth weight infants. Pediatrics 2009;123:e430e437.

7 Doyle LW, Ehrenkranz RA, Halliday HL: Dexamethasone treatment in the first week of life for preventing bronchopulmonary dysplasia in preterm infants: a systematic review. Neonatology 2010;98:217-224.
Doyle LW, Ehrenkranz RA, Halliday HL: Dexamethasone treatment after the first week of life for bronchopulmonary dysplasia in preterm infants: a systematic review. Neonatology 2010;98:289-296.

-9 Ohls RK, Ehrenkranz RA, Wright LL, Lemons JA, Korones SB, Stoll BJ, Stark AR, Shankaran S, Donovan EF, Close NC, Das A: Effects of early erythropoietin therapy on the transfusion requirements of preterm infants below 1,250 grams birth weight: a multicenter, randomized, controlled trial. Pediatrics 2001;108:934-942.

10 Romagnoli C, Zecca E, Gallini F, Girlando P, Zuppa AA: Do recombinant human erythropoietin and iron supplementation increase the risk of retinopathy of prematurity? Eur J Pediatr 2000;159:627-628.

11 Soll RF: Early erythropoietin for preventing red blood cell transfusion in preterm and/or low birth weight infants. Neonatology 2012; 102:127-129.

12 Bahlmann F, De Groot K, Spandau J, Landry A, Hertel B, Duckert T, Boehm S, Menne J, Haller H, Fliser D: Erythropoietin regulates endothelial progenitor cells. Blood 2004;103: 921-926.

13 Heeschen C, Aicher A, Lehmann R, Fichtlscherer S, Vasa M, Urbich C, MildnerRihm C, Martin H, Zeiher A, Dimmeler S: Erythropoietin is a potent physiologic stimulus for endothelial progenitor cell mobilization. Blood 2003;102:1340-1346.

-14 Ozer E, Kumral A, Ozer E, Yilmaz O, Duman N, Ozkal S, Koroglu T, Ozkan H: Effects of erythropoietin on hyperoxic lung injury in neonatal rats. Pediatr Res 2005;58:38-41.
5 Balasubramaniam V, Mervis C, Maxey A, Markham N, Abman S: Hyperoxia reduces bone marrow, circulating, and lung endothelial progenitor cells in the developing lung: implications for the pathogenesis of bronchopulmonary dysplasia. Am J Physiol Lung Cell Mol Physiol 2007;292:L1073-L1084.

16 Burnham E, Taylor W, Quyyumi A, Rojas M, Brigham K, Moss M: Increased circulating endothelial progenitor cells are associated with survival in acute lung injury. Am J Respir Crit Care Med 2005;172:854-860.

- 17 Borghesi A, Massa M, Campanelli R, Bollani L, Tzialla C, Figar T, Ferrari G, Bonetti E, Chiesa G, de Silvestri A, Spinillo A, Rosti V, Stronati M: Circulating endothelial progenitor cells in preterm infants with bronchopulmonary dysplasia. Am J Respir Crit Care Med 2009;180:540-546.

18 Aher S, Ohlsson A: Late erythropoietin for preventing red blood cell transfusion in preterm and/or low birth weight infants. Cochrane Database Syst Rev 2006;3:CD004868.

19 Ohlsson A, Aher SM: Early erythropoietin for preventing red blood cell transfusion in preterm and/or low birth weight infants. Cochrane Database Syst Rev 2006;3:CD004863.

20 Tempera A, Stival E, Piastra M, De Luca D, Ottaviano C, Tramontozzi P, Marconi M, Cafforio C, Marcozzi P, Rossi N, Buffone E: Early erythropoietin influences both transfusion and ventilation needs in very low birth weight infants. J Matern Fetal Neonatal Med 2011;24:1060-1064. 
21 Haiden N, Schwindt J, Cardona F, Schwindt J, Berger A, Klebermass K, Wald M, Kohlhauser-Vollmuth C, Jilma B, Pollak A: Effects of a combined therapy of erythropoietin, iron, folate and vitamin $B_{12}$ on the transfusion requirements of extremely low birth weight infants, Pediatrics 2006;118:20042013.

22 Arcasoy M: The non-haematopoietic biological effects of erythropoietin. Br J Haematol 2008;141:14-31.
23 Foster DJ, Moe OW, Hsia CC: Upregulation of erythropoietin receptor during postnatal and postpneumonectomy lung growth. Am J Physiol Lung Cell Mol Physiol 2004; 287:L1107-L1115.

24 Kovar J, Willet KE, Hislop A, Sly PD: Impact of postnatal glucocorticoids on early lung development. J Appl Physiol 2005;98:881888.

25 Zhang H, Garber SJ, Cui Z, Foley JP, Mohan GS, Jobanputra M, Kaplan F, Sweezey NB, Gonzales LW, Savani RC: The angiogenic factor midkine is regulated by dexamethasone and retinoic acid during alveolarization and in alveolar epithelial cells. Respir Res 2009;10:77.
26 Schneider JK, Gardner DK, Cordero L: Use of recombinant human erythropoietin and risk of severe retinopathy in extremely lowbirth-weight infants. Pharmacotherapy 2008;28:1335-1340.

27 Suk KK, Dunbar JA, Liu A, Daher NS, Leng CK, Leng JK, Lim P, Weller S, Fayard E: Human recombinant erythropoietin and the incidence of retinopathy of prematurity: a multiple regression model. J AAPOS 2008;12: 233-238.

\section{Erratum}

In the article by Rayjada N, Barton L, Chan LS, Plasencia S, Biniwale M, Bui KC: Decrease in Incidence of Bronchopulmonary Dysplasia with Erythropoietin Administration in Preterm Infants: A Retrospective Study. Neonatology 2012;102:287-292 (DOI: $10.1159 / 000341615)$, the following disclosure statement needs to be added:

K.C.B. has a close relation who owns Amgen stocks. 